\title{
Manuais pedagógicas na formação de professores no espaço luso-brasileiro (1870-1970)
}

Pedagogical manuals on teacher education in the

Luso-Brazilian space (1870-1970)

Manuales pedagógicos en la formación de profesores en el espacio luso-brasilero (1870-1970)

Edilene Alexandra Leal Soares

Universidade Federal de Triângulo Mineiro (Brasil)

https://orcid.org/0000-0002-9703-018X

http://lattes.cnpq.br/8990017947382113

edilenealexandra@yahoo.com.br

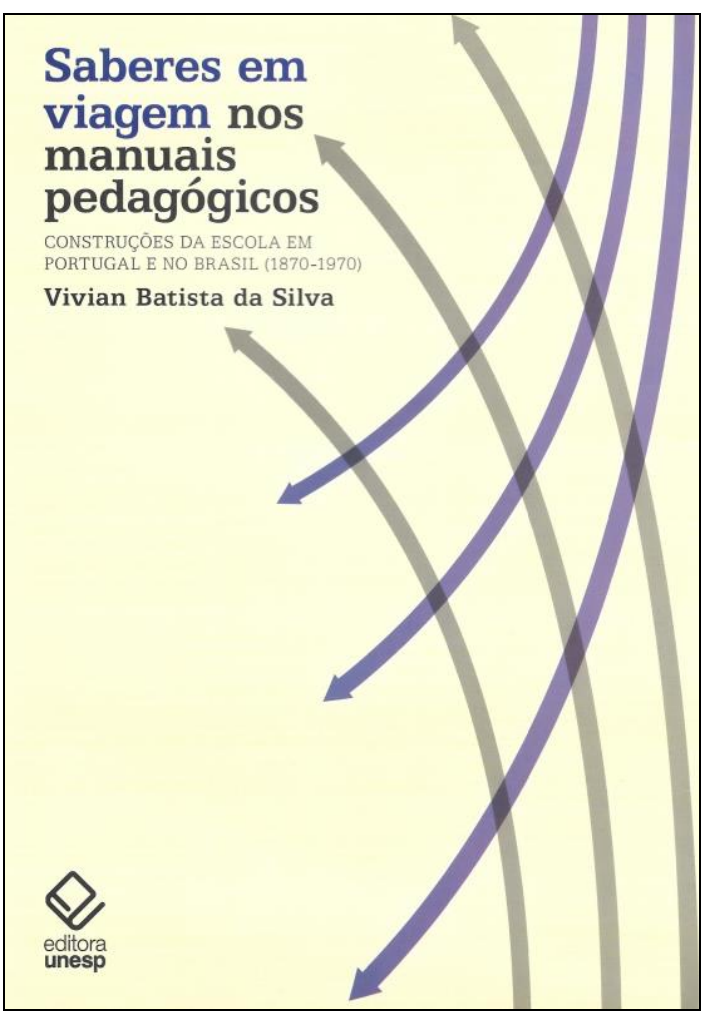

SILVA, Vivian Batista. Saberes em viagem nos manuais pedagógicos. Construções da Escola em Portugal e no Brasil (1870 - 1970). São Paulo: Editora UNESP. 2018. 506p. 
A obra "Saberes em viagem nos manuais pedagógicos. Construções da Escola em Portugal e no Brasil (1870 - 1970)" é leitura essencial aos pesquisadores e interessados em engendrar pelo estudo dos manuais pedagógicos.

Este livro é fruto de uma pesquisa de grande densidade, com realização de investigação meticulosa e análise criteriosa de manuais pedagógicos em circulação no Brasil e em Portugal que eram utilizados na formação de normalistas no período de 1870 a 1970 e, traz à tona as ideias difundidas no processo de formação deste importante ofício da Modernidade.

No período compreendido entre 1870 e 1970 estão incluídas a análise de vinte e cinco manuais pedagógicos de Portugal e cinquenta e cinco do Brasil. Para Silva (2018), os manuais pedagógicos pesquisados eram usados pelas normalistas, o que significa que eles faziam parte do processo de formação, com o objetivo de subsidiar o importante ofício de ensinar, disseminando ideias quanto à centralidade da instituição escolar, seu funcionamento e métodos, enfim, o que instituiria o modelo escolar.

Desta maneira, o marco temporal desta obra, inicia-se em 1870, período de significativas reformas educacionais na França, de consolidação do modelo escolar da Modernidade, por meio da concretização das iniciativas estatais e da busca de disseminação de uma proposta de educação laica, com vistas ao princípio republicano e superação dos valores religiosos, até então predominantes. Deste modo, a escola pública seria a instituição modelar para a consolidação da moral laica republicana.

A obra de Silva (2018) investigou os manuais pedagógicos até a década de 1970, apresentando diversos acontecimentos que fizeram parte dos processos e das ideias que contribuíram para a formação de normalistas e, desta maneira, a autora realizou recortes temporais que moldaram a análise de cada um dos momentos mais importantes.

Silva (2018) contribui para o conhecimento detalhado daquilo que se preconizava nos manuais pedagógicos no período de 1870 a 1970, aos futuros professores do Brasil e Portugal, nas instituições escolares, nomeadamente, escolas normais, que se dedicavam à formação de professores. 
Neste sentido, esta obra apresenta-se como de grande relevância, ainda que não tenha se ocupado diretamente das práticas efetivadas nas escolas primárias pelos professores normalistas, o que seria difícil de realizar, sobretudo, pelas dificuldades relacionadas as fontes de pesquisa e pelo necessário recorte espaço-temporal que teria que ser feito, o trabalho tem o mérito de identificar o que se prescrevia intensamente nos manuais pedagógicos em relação ao ensino e a instituição escolar, justamente, na formação de quadros preparados para tal ofício. Deste modo, a autora realizou leituras de diversos manuais pedagógicos e apreendeu componentes prescritivos essenciais daquilo que deveria ser a escola e a ação dos professores no âmbito da instituição, para mais de uma série de outros elementos concebíveis de se aprofundar.

O livro tem uma introdução densa - "Os manuais pedagógicos e as construções da escola" (SILVA, 17- 62), que aborda desde os fundamentos teóricos da pesquisa até como a investigação foi direcionada, bem como o escopo da apresentação de seus principais resultados. Posteriormente, a obra está dividida em quatro capítulos.

No primeiro capítulo, Silva (2018) relata sobre os manuais pedagógicos utilizados pelos normalistas em Portugal e no Brasil entre 1870 e 1970. No segundo, dedica-se de maneira minuciosa a busca e entendimento das principais obras aludidas pelos autores dos manuais pedagógicos examinados, com a evidente assimilação da ênfase em um pensamento e ou ponto de vista moderna de sociedade.

Em seguida, no terceiro capítulo, aborda os saberes concebidos pelos autores dos manuais pedagógicos, com relevância para os aspectos que dizem respeito: definição do papel do professor (1870/1890); a composição da instituição escolar (1890/1910); a assimilação do aluno (1910/1940); a prescrição de métodos de ensino (1940/1970). As considerações finais encerram a obra com um texto instigante para os leitores.

Os interessados em conhecer "Saberes em viagem nos manuais pedagógicos" encontrarão subsídios para apreender o surgimento destes textos, suas diversas formas de se tornarem obras que participariam do processo de formação de professores. Além disso, a obra de Silva (2018) reporta para outras áreas do conhecimento, expandindo análises condizentes com critérios de uma pesquisa séria e relevante. Sem dúvida, trata-se de uma obra fundamental no âmbito da História da Educação. 